\title{
BMJ Open Protocol of DEXPED trial: efficacy of intravenous dexamethasone, administered at the time of analgesic blocking of the lower limb, on postoperative pain in children: a randomised, placebo-controlled, double-blind trial
}

\author{
Nicolas Vautrin (1) , ${ }^{1}$ Nathalie Thilly, ${ }^{2}$ Yohann Bernard, ${ }^{3}$ François Wurtz, ${ }^{1}$ \\ Claude Meistelman ${ }^{1}$
}

To cite: Vautrin N, Thilly N, Bernard Y, et al. Protocol of DEXPED trial: efficacy of intravenous dexamethasone, administered at the time of analgesic blocking of the lower limb, on postoperative pain in children: a randomised, placebo-controlled, double-blind trial. BMJ Open 2020;10:e036863. doi:10.1136/ bmjopen-2020-036863

- Prepublication history for this paper is available online. To view these files, please visit the journal online (http://dx.doi org/10.1136/bmjopen-2020036863).

Received 11 January 2020 Revised 24 August 2020 Accepted 03 September 2020

Check for updates

(c) Author(s) (or their employer(s)) 2020. Re-use permitted under CC BY-NC. No commercial re-use. See rights and permissions. Published by BMJ.

For numbered affiliations see end of article.

Correspondence to

Dr Nicolas Vautrin;

nicolas_vautrin@hotmail.fr

\section{ABSTRACT}

Introduction Dexamethasone is a drug used to prolong the postoperative analgesia in children after peripheral nerve blockade, although the dose usually used $(0.2 \mathrm{mg} /$ $\mathrm{kg}$ ) has not been studied yet. This study is a monocentric, prospective, randomised, placebo-controlled, doubleblinded study in a university hospital in France. The primary objective of the study is to evaluate the efficacy of $0.2 \mathrm{mg} / \mathrm{kg}$ intravenous dexamethasone on early postoperative pain in children aged $6-15$ years, who require a lower limb peripheral nerve block following general anaesthesia.

Methods and analysis Eighty children, aged 6-15 years, undergoing surgery for which peripheral nerve lower limb blockade with ropivacaine following general anaesthesia are included. The inclusion criteria are: children aged 6-15 years, with American Society of Anaesthesiologists physical status I or II and scheduled for surgery requiring a peripheral block of the lower limb for analgesic purposes, with a preoperative anaesthetic evaluation between 90 and 2 days before the surgery, with informed consent from legal representatives. General anaesthesia is performed. The patient receives, according to his group, either $0.2 \mathrm{mg} / \mathrm{kg}$ of dexamethasone intravenously at the start of anaesthetic induction or the same volume of placebo. Then, the peripheral block of the lower limb is performed with ropivacaine. The primary outcome is the total doses of opioid administered (in $\mathrm{mg} / \mathrm{kg}$ of morphine equivalent) within 24 hours postoperatively. The secondary objectives are the evaluation of the effect of a single-dose intravenous dexamethasone at the time of anaesthetic induction, on the following parameters: onset of postoperative pain, duration of motor block, postoperative nausea and vomiting within 24 hours.

Ethics and dissemination This study is conducted according to the principles of the Declaration of Helsinki and has been approved by the French national ethics committee and the National Drug Safety Agency. Findings of this study will be widely disseminated through
Strengths and limitations of this study

- This is a randomised, controlled, double-blind study, a design which should provide a high level of evidence.

- This is the first trial investigating the analgesic efficacy of a dose of dexamethasone $0.2 \mathrm{mg} / \mathrm{kg}$ intravenously in addition to local analgesics peripheral nerve block in children.

- The main limitation is the monocentric design.

- The study focuses on children aged 6-15 years in order to have a reliable self-assessment of pain using verbal analogic pain scale; in consequence, the results may not be applicable to younger children.

conference presentations, reports, factsheets and academic publications.

Trial registration number NCT03618173.

\section{INTRODUCTION}

\section{Background and rationale}

Regional anaesthesia is a technique that transiently abolishes the transmission of nerve impulses to a precise area of the body. This technique is becoming more popular for the management of the surgical patient. It allows faster recovery in the immediate postoperative (early rehabilitation) period, promoting outpatient surgery and reducing the length of stay ${ }^{1-5}$ and hospital costs. ${ }^{6}{ }^{7}$ It can be performed alone or combined with general anaesthesia. In the latter case, the main benefit of a regional technique is to provide better per operative and postoperative analgesia. There are different types of 
locoregional anaesthesia: the central blocks (epidural anaesthesia, caudal anaesthesia and spinal anaesthesia); the perineural peripheral blocks (ultrasound-guided injection of local anaesthetic in direct contact with a nerve to block its conduction) and the diffusion peripheral blocks (ultrasound-guided injection of local anaesthetic in an anatomic space with passive and random diffusion of the drug).

Dexamethasone is used in adults, ${ }^{8-10}$ by the direct intravenous route or in addition to local anaesthetics when performing a loco-regional anaesthesia. ${ }^{11-16}$ Several studies have shown the benefits of addition of dexamethasone. Desmet et $a l^{14}$ showed a higher efficacy of dexamethasone intravenous $(10 \mathrm{mg})$ and perineural $(10 \mathrm{mg})$ in interscalene block (brachial plexus block) in 150 patients, compared with placebo treatment. There was 1405 min between block completion and the first analgesic dose for the perineural dexamethasone group vs $1275 \mathrm{~min}$ for the dexamethasone intravenous group and 757 min for the placebo group $(\mathrm{p}<0.0001)$.

In children, dexamethasone is a drug that has marketing authorisation from birth. ${ }^{17}$ It can be injected intravenously for postoperative analgesia as in adults ${ }^{18}$ or in central caudal anaesthesia ${ }^{19-21}$ in association with local anaesthetic.

Two studies have been published on the efficacy of dexamethasone intravenous injection in diffusion blocks. ${ }^{22}{ }^{23}$ Shirazi et al found an efficacy of $0.5 \mathrm{mg} / \mathrm{kg}$ dexamethasone intravenously, as compared with placebo, in 42 children aged between 1 and 6 years undergoing surgical treatment of hypospadias after a penile block. The primary outcome was the pain level after $0,2,6,12$ and 24 hours, assessed by using the Face Legs Activity Cry Consolability pain scale in the recovery room 2, 6, 12 and 24 hours after dexamethasone administration. There was a benefit for the dexamethasone group with a pain score at respectively 2, 1, 1, 1 and 2 versus respectively 8, 8, 7, 7 and 8 for the placebo group $(\mathrm{p}<0,0001)$. Mohamed et $a l^{23}$ have demonstrated the benefit of intravenous dexamethasone in addition to an oropharyngeal regional block for analgesia after tonsillectomy in 150 children aged 2-12 years, randomised into three groups: a dexamethasone intravenous group $0.5 \mathrm{mg} / \mathrm{kg}$, a single glossopharyngeal block group and a group combining both techniques.

Postoperative pain (as measured by a 10-fold rating scale) was decreased in the combination group, with an increased delay in the first use of analgesics $(p=0.0001)$

Other studies on dexamethasone efficacy as an adjuvant to central caudal blocks ${ }^{19-21} 24$ include the placebo study by Hong et al. ${ }^{19}$ The authors investigated the use of morphine or paracetamol in the postoperative period in 77 children aged 1-5 years, after orchidopexy under general anaesthesia combined with caudal anaesthesia. The children were randomised in two groups: dexamethasone intravenous $0.5 \mathrm{mg} / \mathrm{kg}$ at the time of anaesthetic induction, or intravenous injection of isotonic saline. A significantly lower percentage of patients used opioids in the dexamethasone group $(7.9 \%)$, as compared with the placebo group $(38.5 \%)(\mathrm{p}<0.01)$. Moreover, the use of paracetamol was lower in the dexamethasone group (respectively $25.7 \%$ vs $89.3 \%, \mathrm{p}<0.001$ ) with a delay between intravenous injection and first dose of 646 vs $430 \min (\mathrm{p}<0.001)$.

These studies have shown a decrease in postoperative pain, measured by a visual analogue scale (VAS), and analgesic consumption. However, no study has been conducted up to now during orthopaedic surgery in association with a peripheral nerve block.

Although a dose of $0.5 \mathrm{mg} / \mathrm{kg}$ of dexamethasone intravenously was used in the previous studies, this dose has been shown to increase significantly the incidence of postoperative bleeding with a relative risk of $6.8,{ }^{25}$ whereas lower doses $(0.15 \mathrm{mg} / \mathrm{kg})$ were not correlated with a risk of bleeding.

To limit this major risk, a dose of $0.2 \mathrm{mg} / \mathrm{kg}$ dexamethasone-between $0.1 \mathrm{mg} / \mathrm{kg}$ (prevention of postoperative nausea and vomiting (PONV)) and $0.5 \mathrm{mg} / \mathrm{kg}$ (antiinflammatory dose)—is often used in routine practice. However, no study has evaluated the efficacy of such a dose to reduce postoperative pain. Moreover, the dose providing an improvement of the sensory block without prolongation of the motor block remains unknown. Dexamethasone is a glucocorticoid with a dose-dependent risk of hyperglycaemia, ${ }^{26}$ therefore, it is very important to find the efficacy of lowest dose.

Finally, the safety of local anaesthetics is of importance in children because of their lower weight than adults, with a much lower toxicity threshold. The use of an effective adjuvant could allow to use a higher dilution of local anaesthesic drug while conserving and potentiating their analgesic effects.

We have designed a prospective, randomised, placebocontrolled, double-blind trial to assess the efficacy on postoperative pain of dexamethasone intravenous $0.2 \mathrm{mg} / \mathrm{kg}$ after a peripheral block of the lower limb with ropivacaine in children.

\section{Objectives}

\section{Primary objective}

The primary objective of the study is to evaluate the efficacy on early postoperative pain (first 24 hours) in children aged 6-15 years, compared with placebo, of intravenous dexamethasone at a single dose of $0.2 \mathrm{mg}$ / $\mathrm{kg}$ given as a bolus at the time of anaesthetic induction. The study is limited to surgical procedures requiring a perineural peripheral block of the lower limb with ropivacaine after general anaesthesia.

\section{Secondary objectives}

The secondary objectives are to evaluate the effect of a single-dose intravenous dexamethasone at the time of anaesthetic induction, on the following outcomes:

- Onset of postoperative pain.

- Duration of motor block

- PONV within 24 hours. 


\section{METHODS AND ANALYSIS}

\section{Trial design}

The DEXamethasone in PEDiatric postoperative analgesia (DEXPED) study is a monocentric, randomised, controlled, double-blind, parallel-group clinical trial with two groups: one receiving a single dose of $0.2 \mathrm{mg} / \mathrm{kg}$ intravenous dexamethasone at the anaesthesia induction and the other the same volume of physiological saline $0.9 \%$ (placebo). Patients' recruitment started in December 2019 for a total duration of 24 months.

\section{Study setting}

The study is performed in Nancy University Hospital which is the sponsor. The study protocol complies with the 2013 Standard Protocol Items: Recommendations for Interventional Trials statement (figure 1) and the reporting with the 2010 Consolidated Standards of Reporting Trials statement (figure 2). The study protocol has been registered before the patients' recruitment in the European Clinical Trials Database (EudraCT) of the European Medicine Agency (2018-000314-38), as well as on ClinicalTrials.gov (NCT03618173).

\section{Inclusion criteria}

The inclusion criteria are: (1) children aged 6-15 years, (2) American Society of Anaesthesiologists physical status I or II, (3) scheduled for surgery requiring a peripheral block of the lower limb for analgesic purposes, (4) with a preoperative anaesthetic evaluation between 90 and 2 days before the surgery, (5) with informed consent from legal representatives. (6) children covered by the French Health Insurance.

\section{Exclusion criteria}

The exclusion criteria are: (1) contraindication of dexamethasone as a single injection or in combination with a non-recommended drug, (2) septic surgery or ongoing infection, (3) steroid treatment during the 7 days preceding the surgery, (4) history of diabetes, (5) ambulatory surgery, (6) disabilities or developmental delay compromising the self-assessment of pain, (7) uncontrolled psychotic state, (8) installation of a peripheral nerve catheter, (9) pre-existing neurological disease, (10) chronic opioid use, (11) body mass index $>99$ th percentile for age, (12) persons deprived of liberty by a judicial or administrative decision (articles L.1121-5 to L.1121-8 and L.1122-2 of the French Public Health Code) and persons receiving psychiatric care (Articles L.3212-1 and L.3213-1).

\section{Randomisation and blinding}

Eligible patients are randomly assigned (1:1) to one of the two groups: the experimental group receiving dexamethasone and the control group receiving placebo. A block randomisation (blocks of four), stratified on the level of pain induced by surgical planned procedures (surgery known to induce low-to-moderate pain vs very painful surgery), is realised by using a computer random number generator. Surgeries inducing low-to-moderate pain include tendon surgery, material removal, cyst surgery, minor exostosis. Very painful surgeries include all major bone surgical procedures: osteotomy, major exostosis, limb lengthening, bone or articular prothesis. The anaesthesiologist can adapt this classification according to the global clinical situation of the patient. The randomisation numbers combined with the allocated treatment arm (dexamethasone or placebo) are put in sealed envelopes and opened just before surgery. Included patients and their legal representatives, physicians, nursing staff, investigator and clinical research nurses are blinded to treatment. Only the study pharmacy of the University Hospital of Nancy knows which participant/code is allocated to which treatment arm. The investigator will unblind the treatment allocation if this is relevant to the safety of the included patient.

For each participating patient, anonymised data are collected from electronic medical records on a standardised paper case report form (CRF) by clinical research nurses who have regular Good Clinical Practice trainings, under the supervision of the investigator.

\section{Study organisation}

There is a steering and scientific committee in charge of supervising all scientific aspects and organisational issues occurring during the study period. It initially determines the methodology and decides in the course of the research of the response to be made in unforeseen cases. It comprises two clinicians (anaesthesiologists) and a methodologist. It will meet three times during the preparation of the study (drafting of the protocol and the paper CRF), in the middle of the inclusion period to evaluate the progress of the study and at the end of the study for the analysis and interpretation of results.

This study is also followed by a data monitoring and safety committee (DMSC). The DMSC is independent of the trial investigators and performs an ongoing review of safety parameters and overall study conduct. The DMSC comprises two independent clinicians (anaesthesiologists). The committee meets on a conference call three times up to the completion of the study.

\section{Patient and public involvement}

No patients or members of the public were involved in the development, planning, recruitment, conduction or burden assessment of this study. After completion of the study, an information letter about the results will be provided for study participants.

\section{Description of the study flow and interventions}

Time $n^{\circ} 1$ : pre-anaesthetic evaluation (screening visit)

During the pre-anaesthetic evaluation, performed between 90 and 2 days before the surgery, the eligibility criteria are checked. If eligible, a detailed information form that explains the objectives/procedures of the proposed study, the tests required and possible risks is given to the child and his (her) legal representatives. 


\begin{tabular}{|c|c|c|c|c|c|}
\hline & \multicolumn{5}{|c|}{ STUDY PERIOD } \\
\hline & \multirow{2}{*}{$\begin{array}{l}\text { Enrolment } \\
\text { Screening } \\
D-90 \text { to }-2\end{array}$} & \multirow{2}{*}{$\begin{array}{l}\text { Allocation } \\
\mathrm{J}-1 \text { or } \mathrm{J} 0\end{array}$} & \multicolumn{3}{|c|}{ Post-allocation } \\
\hline TIMEPOINT ${ }^{\star \star}$ & & & $\begin{array}{c}\text { Per } \\
\text { operative } \\
\text { period }\end{array}$ & $\begin{array}{c}\text { Post- } \\
\text { operative } \\
\text { care } \\
\text { room } \\
\end{array}$ & $\begin{array}{l}\text { Surgical unit (post- } \\
\text { operative 24h) }\end{array}$ \\
\hline \multicolumn{6}{|l|}{ ENROLMENT: } \\
\hline \multirow{5}{*}{$\begin{array}{r}\text { Demographics } \\
\text { Comorbidities and } \\
\text { treatments } \\
\text { Clinical examination } \\
\text { Eligibility } \\
\text { screen } \\
\text { Informed consent }\end{array}$} & $x$ & & & & \\
\hline & $x$ & & & & \\
\hline & $x$ & & & & \\
\hline & $\mathrm{X}$ & $\mathrm{X}$ & & & \\
\hline & & $x$ & & & \\
\hline Randomisation & & $\mathrm{X}$ & & & \\
\hline Allocation & & $\mathrm{X}$ & & & \\
\hline \multicolumn{6}{|l|}{ INTERVENTIONS: } \\
\hline \multirow{2}{*}{$\begin{array}{r}\text { IV dexamethasone } \\
\text { IV placebo } \\
\text { (physiologic serum) }\end{array}$} & & & $x$ & & \\
\hline & & & $\mathrm{X}$ & & \\
\hline \multicolumn{6}{|l|}{ ASSESSMENTS: } \\
\hline \multirow{2}{*}{$\begin{array}{r}\text { Surgery name } \\
\text { Type and time of } \\
\text { block onset }\end{array}$} & & & $\mathrm{X}$ & & \\
\hline & & & $\mathrm{X}$ & & \\
\hline \multirow{2}{*}{$\begin{array}{r}\text { Lasting of surgery } \\
\text { Dose of sufentanil } \\
\text { used }\end{array}$} & & & $x$ & & \\
\hline & & & $x$ & & \\
\hline \multicolumn{6}{|l|}{$\begin{array}{r}\text { Dose and time of } \\
\text { paracetamol injection }\end{array}$} \\
\hline \multicolumn{6}{|l|}{$\begin{array}{r}\text { Dose and time of anti- } \\
\text { emetic injection }\end{array}$} \\
\hline \multicolumn{6}{|l|}{$\begin{array}{r}\text { Dose and time of } \\
\text { morphinic injection }\end{array}$} \\
\hline \multicolumn{6}{|l|}{ Bromage score } \\
\hline Adverse events & & & & & \\
\hline
\end{tabular}

Figure 1 Schedule of enrolment, interventions and assessments (Standard Protocol Items: Recommendations for Interventional Trials 2013).

Time $\mathrm{n}^{\circ}$ 2: pre-anaesthetic visit (inclusion visit)

During the pre-anaesthetic visit, performed the day of the surgery or the day before depending on the patient's admission day, eligible criteria are checked again. If the child is eligible and the legal representatives agree for his 


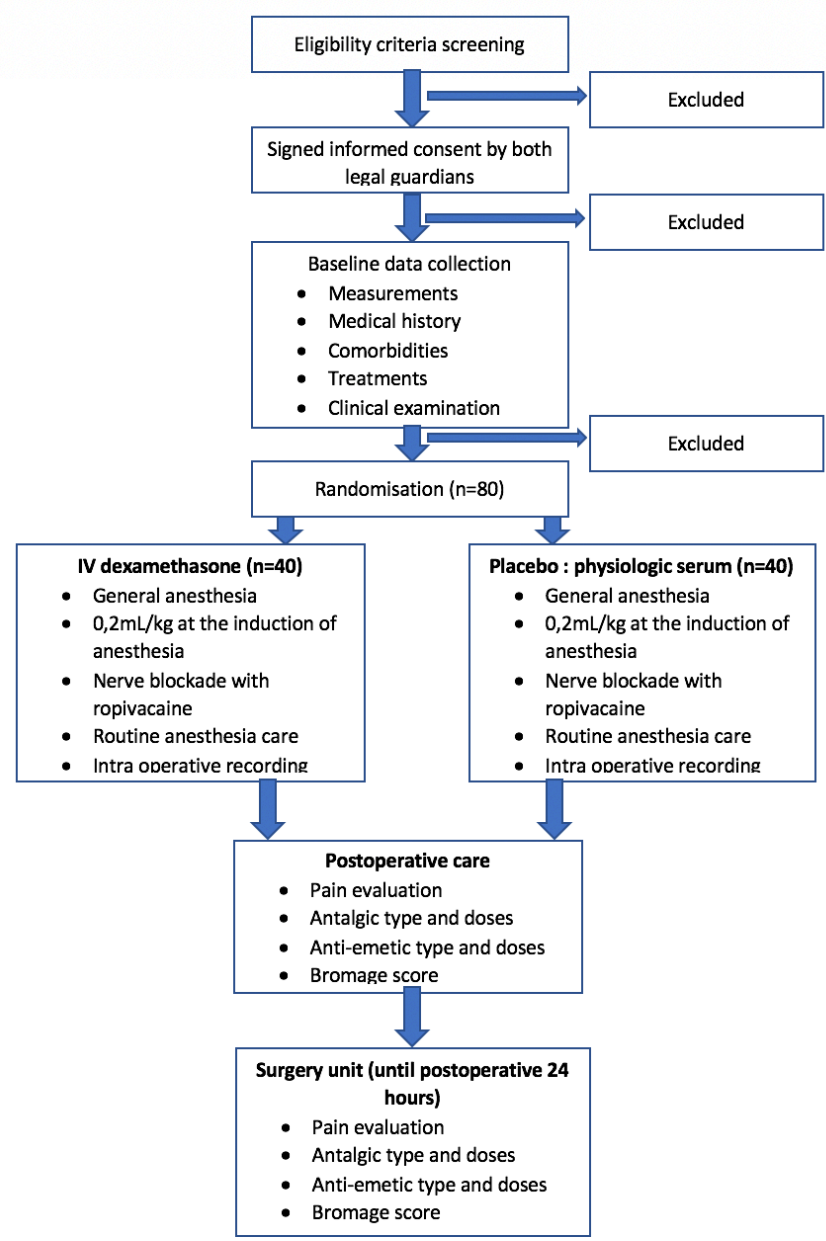

Figure 2 Study flow chart (Consolidated Standards of Reporting Trials statement).

(her) participation in the study, they signed a consent form to participate.

The randomisation is then carried out and the anaesthesiologist informs the hospital pharmacy, on a specific form on the day of the procedure or the day before. A syringe of the treatment allocated by the randomisation is then prepared by the pharmacy staff the morning of surgery, and sent to the operating room.

Time $n^{\circ} 3$ : surgical procedure

All included patients receive midazolam $0.3 \mathrm{mg} / \mathrm{kg}$ orally (maximum $10 \mathrm{mg}$ ) $30 \mathrm{~min}$ before surgery. Anaesthesia is induced by inhaled sevoflurane, followed by intravenous injection of sufentanil $0.2 \mu \mathrm{g} / \mathrm{kg}$ and propofol $2-3 \mathrm{mg} /$ $\mathrm{kg}$. The patient receives, according to his group, either $0.2 \mathrm{~mL} / \mathrm{kg}(=0.2 \mathrm{mg} / \mathrm{kg})$ maximum dose $8 \mathrm{mg}$ of intravenous dexamethasone at the start of induction of anaesthesia or the same volume of placebo (physiological saline). Then, the block of the lower limb is performed with $0.3 \mathrm{~mL} / \mathrm{kg}$ ropivacaine (concentration of $2 \mathrm{mg} / \mathrm{mL}$ ) ultrasound-guided with or without neurostimulation.

Sevoflurane is used for the maintenance of general anaesthesia with reinjection of sufentanil at the discretion of the anaesthesiologist.

Thirty minutes before the end of the surgical procedure, the patient is given paracetamol $15 \mathrm{mg} / \mathrm{kg}$ intravenously.

After the completion of the surgical procedure, the child is admitted to the postanaesthesia care unit (PACU). Pain intensity is evaluated using a VAS, validated from the age of 6 years (figure 3), rating from 0 (no pain) to 100 (maximum pain intensity imaginable). Occurrence of PONV and the Bromage score are also evaluated.

When the initial VAS in PACU is between 30 and 60 despite level 1 analgesic medications, nalbuphine $0.2 \mathrm{mg} / \mathrm{kg}$ intravenously is given whereas when initial VAS in PACU is between 70 and 100 , morphine $0.1 \mathrm{mg} /$ $\mathrm{kg}$ (maximum: $3 \mathrm{mg}$ ) every $4-6$ hours is administered.

In the case of postoperative nausea and/or vomiting, ondansetron $0.1 \mathrm{mg} / \mathrm{kg}$ every 8 hours is administered if it persists for further $30 \mathrm{~min}$, droperidol $10 \mu \mathrm{g} / \mathrm{kg}$ is given every 8 hours.

The patient returns to the surgical ward after 1-2 hours in the PACU with regular evaluation (every 4 hours) of pain, nausea/vomiting, and the Bromage score. Each included patient is followed up for 24 hours after the end of the surgery.

\section{POSTOPERATIVE PAIN SCALE}
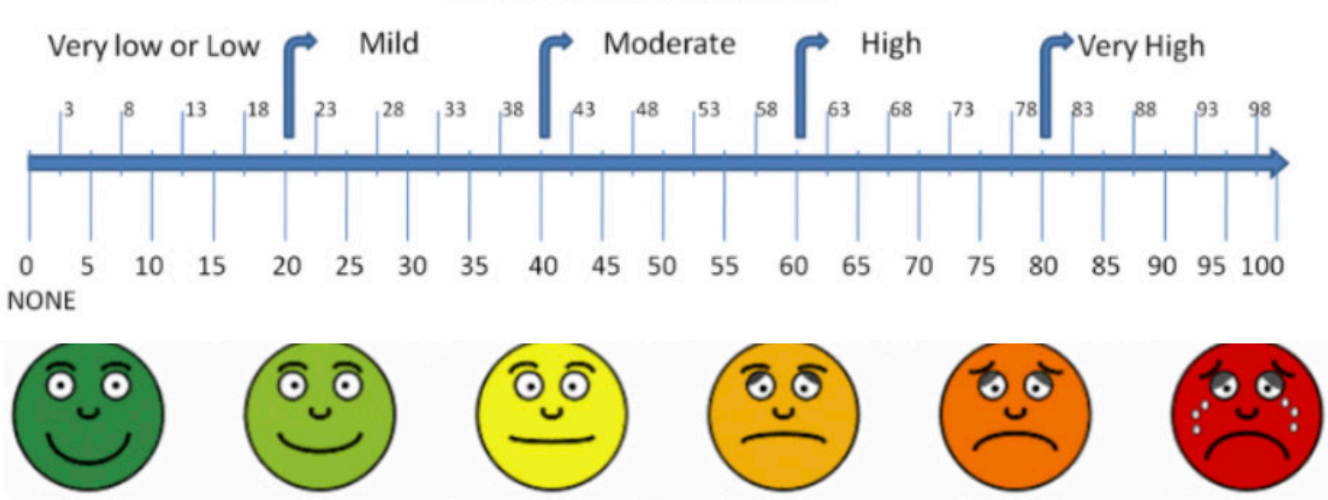

Figure 3 Visual analogue scale. 


\section{Drug management}

Drugs are prepared in the hospital pharmacy, in a plastic syringe the morning of surgery and packaged in a sealed plastic bag according to the randomisation plan.

A randomisation code is attached to each syringe to guarantee the blinding.

\section{OUTCOMES, MEASUREMENTS AND DATA COLLECTION Primary outcome}

The primary outcome is the total consumption of opioids (in milligram per kilogram of morphine equivalent) within the first 24 hours postoperatively.

\section{Secondary outcomes}

Secondary outcomes include: (1) the delay (in minutes) between the block completion and the first administration of opioids during the postoperative 24 hours; (2) the duration of the motor block, evaluated by the modified Bromage score; (3) the occurrence and the importance of postoperative nausea and/or vomiting, evaluated by the quantity of anti-emetics (ondansetron, droperidol) administered during the postoperative 24 hours.

\section{Data registration}

The following data are collected:

\section{Preoperative data}

During the pre-anaesthetic visit and after receiving the informed consent, inclusion criteria as well as sociodemographic medical information are collected: sex, month and year of birth, comorbidities and current treatments. A clinical examination is carried out with recording of weight, height, blood pressure and heart rate.

\section{Per operative data}

During the surgery, the type of the surgery and the pain it induces (low/medium vs very painful), the time of the start and end of the surgical procedure, the use of a tourniquet, the type of the block (femoral, sciatic, etc) and its time of performance are collected.

The time and doses of all analgesic medications and anti-emetic treatment are also collected.

\section{Postoperative data}

In the PACU and the surgical ward, results of VAS (from 0 to 100) and nausea/vomiting evaluations (no nausea/ vomiting, nausea without vomiting, nausea and vomiting) are collected (table 1).

\begin{tabular}{ll}
\hline Table 1 Treatments of nausea and vomiting & \\
\hline Postoperative nausea and vomiting & Treatment \\
\hline No nausea/vomiting & Nothing \\
Nausea & Anti-emetic \\
Vomiting & Anti-emetic \\
Nausea and vomiting & Anti-emetic \\
\hline
\end{tabular}

\begin{tabular}{|c|c|}
\hline Score & Criteria \\
\hline 1 & Complete block (unable to move knee or feet) \\
\hline 2 & Almost complete block (able to move feet only) \\
\hline 3 & Partial block (able to move knee only) \\
\hline 4 & $\begin{array}{l}\text { Detectable weakness of hip flexion while supine (full } \\
\text { flexion of knee) }\end{array}$ \\
\hline 5 & No detectable weakness of hip flexion while supine \\
\hline 6 & Able to perform partial knee bend \\
\hline
\end{tabular}

Time and doses of all analgesic medications (paracetamol, ketoprofren, nalbuphine and morphine), antiemetic (ondansetron and droperidol) and modified Bromage score $^{27}$ (motor block evaluation score ranging from 0 (complete motor block) to 6 (no motor block)) (table 2) are also collected.

Patients' consents and data collected are checked for completeness by trained clinical assistants from the sponsor (University Hospital of Nancy).

\section{SAFETY}

Every serious adverse event (SAE) that may be related to the studied treatment or not, expected or unexpected, is reported within 24 hours by the investigator to the sponsor on a SAE form. SAE are also submitted to the DMSC.

If they are unexpected, they are listed as being suspected unexpected SAR and notified in a report by the sponsor to Eudravigilance (European pharmacovigilance database).

\section{STATISTICAL ANALYSIS AND SAMPLE SIZE CALCULATION Sample size estimation}

Based on our practices and published results in adult, ${ }^{28}$ we estimate that the mean morphine doses administered in the placebo group is $0.7 \pm 0.6 \mathrm{mg} / \mathrm{kg}$ for the 24 first hours and that dexamethasone would reduce these doses by $50 \%(0.3 \mathrm{mg} / \mathrm{kg} /$ day of morphine in the dexamethasone group). Considering an alpha risk of $5 \%$ and a power of $80 \%$, and based on the two-sample independent t-test, it is necessary to include 36 patients per group to demonstrate a statistically significant difference.

As a safety measure and to take into account possible premature stoppages and/or unusable results, we plan to include 40 patients in each group (according to parametric vs non-parametric statistics in the analysis of randomised trials with non-normally distributed data, BMC Medical Research Methodology, 2005).

\section{Statistical analysis}

The analysis of the results is performed using SAS software V.9.4 (SAS Institute, Cary, North Carolina, USA).

A descriptive analysis and a comparison of the main sociodemographic and medical characteristics between 
the two study groups is scheduled, using a $\chi^{2}$ test for qualitative variables and a Student's t-test for quantitative variables. Then, the total amount of nalbuphine or morphine-in morphine equivalent-administered during the first 24 hours, as well as the three secondary outcomes, are compared between the two groups by using a Mann-Whitney U test or a generalised linear model with adjustment for the patients' characteristics if they differ between groups.

A $p$ value of $<0.05$ for two-sided tests is considered significant. All analyses are performed according to the intention-to-treat principle. In case of unblinding or for patients quitting the study before the end of follow-up, the measurements will be continued (if possible).

\section{ETHICS AND DISSEMINATION}

This study is conducted according to the principles of the Declaration of Helsinki and has been approved by the French national ethics committee (Comite de Protection des Personnes Sud Méditerrannée III, Nîmes, France, reference number 2018.07.10 cinq) and the National Drug Safety Agency (Agence Nationale de Sécurité du Médicament, reference number MEDMSANAT-2019-09-00262). Findings of this study will be widely disseminated through conference presentations, reports, factsheets and academic publications and generalisation will be further discussed.

\section{Consent}

A patient information sheet is offered to each child according to his age and to their legal representatives. Patients are informed of the risks of dexamethasone and the study's objectives when they are recruited. All questions regarding the study are answered by the recruiting anaesthesiologist. The patient and the legal representatives get time ( 48 hours) to consider if they wish to participate. The patient is informed that he or she can cancel or pause participation in the study for any reason at any time. The withdrawal or suspension of participation does not affect the medical or other treatment of the patient. Participating patients do not incur any costs and no compensation will be paid to patients or any other person involved in the study.

\section{DISCUSSION}

\section{Strengths and limitations}

This is a randomised, controlled, double-blind study, a design which should provide a high level of evidence.

This is the first trial investigating the analgesic efficacy of a dose of dexamethasone $0.2 \mathrm{mg} / \mathrm{kg}$ intravenously in addition to local analgesics peripheral nerve block in children. The previous studies using a dose of $0,5 \mathrm{mg} / \mathrm{kg}$ may have showed to be associated with a risk of postoperative bleeding. Moreover, $0.2 \mathrm{mg} / \mathrm{kg}$ is the dose used in routine practice. To our knowledge, this dose has never been studied in children.
The main limitation is the monocentric design. The Nancy Hospital is a university hospital and a reference centre throughout the Lorraine region in France. We cannot exclude that paediatric patients undergoing surgery in this centre have a particular profile that could limit the generalisation of our results.

Also, the study focuses on children aged 6-15 years in order to have a reliable self-assessment of pain using VAS. In consequence, the results may not be applicable to younger children.

In summary, this trial is the first study of the efficacy of $0.2 \mathrm{mg} / \mathrm{kg}$ intravenous dexamethasone after a lower limb peripheral nerve block with ropivacaine on postoperative analgesia care in children.

If DEXPED yields positive results, it will provide a significant contribution to the development of paediatric multimodal analgesia and justify scientifically what is done in routine practice.

\section{Trial status}

Protocol V.3: 22 August 2020.

Inclusion starting: 16 December 2019.

Recruitment complete: 16 December 2021.

\section{Author affiliations}

${ }^{1}$ Département d'Anesthesie-Réanimation, Université de Lorraine, Nancy, Lorraine, France

${ }^{2}$ Plateforme d'Aide à la Recherche Clinique, Université de Lorraine, Nancy, Lorraine, France

${ }^{3}$ Département Méthodologie Promotion Investigation, Université de Lorraine, Nancy, Lorraine, France

Acknowledgements The authors would like to thank Nadine Petitpain for providing critical input to the pharmacovigilance part of the protocol; Nourredine Harbi for providing critical input to the data monitoring part of the protocol and Michel Prévot for providing critical input to the pharmacy part of the protocol. The authors would also like to thank all the medical and paramedical team who took part in the care of the patients as part of this study.

Collaborators Nadine Petitpain Nourredine Harbi Michel Prévot

Contributors NV contributed to the conception and design of the research protocol. NT and CM provided critical input pertaining to the design of the trial interventions and procedures. NV wrote the first draft of the protocol and this manuscript. NT designed the statistical analysis plan. All authors (NT, YB, CM and FW) critically revised and modified the protocol and the article. They all approved the final version to be published.

Funding The authors have not declared a specific grant for this research from any funding agency in the public, commercial or not-for-profit sectors.

Competing interests None declared.

Patient and public involvement Patients and/or the public were not involved in the design, or conduct, or reporting, or dissemination plans of this research.

Patient consent for publication Not required.

Provenance and peer review Not commissioned; externally peer reviewed.

Open access This is an open access article distributed in accordance with the Creative Commons Attribution Non Commercial (CC BY-NC 4.0) license, which permits others to distribute, remix, adapt, build upon this work noncommercially, and license their derivative works on different terms, provided the original work is properly cited, appropriate credit is given, any changes made indicated, and the use is non-commercial. See: http://creativecommons.org/ licenses/by-nc/4.0/.

ORCID iD

Nicolas Vautrin http://orcid.org/0000-0003-3628-9208 


\section{REFERENCES}

1 Wulf $\mathrm{H}$, Löwe J, Gnutzmann K-H, et al. Femoral nerve block with ropivacaine or bupivacaine in day case anterior crucial ligament reconstruction. Acta Anaesthesiol Scand 2010;54:414-20.

2 Schug SA, Chong C. Pain management after ambulatory surgery. Curr Opin Anaesthesiol 2009;22:738-43.

3 Ludot H, Berger J, Pichenot V, et al. Continuous peripheral nerve block for postoperative pain control at home: a prospective feasibility study in children. Reg Anesth Pain Med 2008;33:52-6.

4 Horn EP, Schroeder F, Wilhelm S, et al. Wound infiltration and drain lavage with ropivacaine after major shoulder surgery. Anesth Analg 1999;89:1461.

5 Mulroy MF, Burgess FW, Emanuelsson BM. Ropivacaine $0.25 \%$ and $0.5 \%$, but not $0.125 \%$, provide effective wound infiltration analgesia after outpatient hernia repair, but with sustained plasma drug levels. Reg Anesth Pain Med 1999;24:136-41.

6 Ilfeld BM, Mariano ER, Williams BA, et al. Hospitalization costs of total knee arthroplasty with a continuous femoral nerve block provided only in the hospital versus on an ambulatory basis: a retrospective, case-control, cost-minimization analysis. Reg Anesth Pain Med 2007;32:46-54.

7 Lintner S, Shawen S, Lohnes J, et al. Local anesthesia in outpatient knee arthroscopy: a comparison of efficacy and cost. Arthroscopy 1996;12:482-8.

8 Waldron NH, Jones CA, Gan TJ, et al. Impact of perioperative dexamethasone on postoperative analgesia and sideeffects: systematic review and meta-analysis. $\mathrm{Br} J$ Anaesth 2013;110:191-200.

9 De Oliveira GS, Almeida MD, Benzon HT, et al. Perioperative single dose systemic dexamethasone for postoperative pain: a meta-analysis of randomized controlled trials. Anesthesiology 2011;115:575-88.

10 Salengro A. Analgésie postopératoire _dexamethasone pour tous les patients ? Paris: MAPAR, 2010: 575-81.

11 Woo JH, Kim YJ, Kim DY, et al. Dose-dependency of dexamethasone on the analgesic effect of interscalene block for arthroscopic shoulder surgery using ropivacaine $0.5 \%$ : A randomised controlled trial. Eur J Anaesthesiol 2015;32:650-5.

12 Cummings KC, Napierkowski DE, Parra-Sanchez l, et al. Effect of dexamethasone on the duration of interscalene nerve blocks with ropivacaine or bupivacaine. Br J Anaesth 2011;107:446-53.

13 Abdallah FW, Johnson J, Chan V, et al. Intravenous dexamethasone and perineural dexamethasone similarly prolong the duration of analgesia after supraclavicular brachial plexus block: a randomized, triple-arm, double-blind, placebo-controlled trial. Reg Anesth Pain Med 2015;40:125-32.
14 Desmet M, Braems H, Reynvoet M, et al. I.V. and perineural dexamethasone are equivalent in increasing the analgesic duration of a single-shot interscalene block with ropivacaine for shoulder surgery: a prospective, randomized, placebo-controlled study. $\mathrm{Br} \mathrm{J}$ Anaesth 2013;111:445-52.

15 Rosenfeld DM, Ivancic MG, Hattrup SJ, et al. Perineural versus intravenous dexamethasone as adjuncts to local anaesthetic brachial plexus block for shoulder surgery. Anaesthesia 2016;71:380-8.

16 Rahangdale R, Kendall MC, McCarthy RJ, et al. The effects of perineural versus intravenous dexamethasone on sciatic nerve blockade outcomes. Anesthesia \& Analgesia 2014;118:1113-9.

17 Fiche produit RCP dexaméthasone ANSM, 2010. Available: http:// agence-prd.ansm.sante.fr/php/ecodex/rcp/R0182896.htm

18 La Brière De F, Ecoffey C. Analgésie en pédiatrie. SFAR, Paris, 2013: 1-20. https://sofia.medicalistes.fr/spip/IMG/pdf/Analgesie_en_ pediatrie.pdf

19 Hong J-Y, Han SW, Kim WO, et al. Effect of dexamethasone in combination with caudal analgesia on postoperative pain control in day-case paediatric orchiopexy. Br J Anaesth 2010;105:506-10.

20 Murni Sari Ahmad A, Azarinah I, Esa K, et al. Intravenous dexamethasone in combination with caudal block prolongs postoperative analgesia in pediatric daycare surgery. Middle East $J$ Anaesthesiol 2015;23:177-83.

21 Zhu C, Zhang S, Gu Z, et al. Caudal and intravenous dexamethasone as an adjuvant to pediatric caudal block: a systematic review and meta-analysis. Paediatr Anaesth 2018;28:195-203.

22 Shirazi M, Mahmoudi $\mathrm{H}$, Nasihatkon B, et al. Efficacy of dexamethasone on postoperative analgesia in children undergoing hypospadias repair. Pak J Med Sci 2016;32:125-9.

23 Mohamed SK, Ibraheem AS, Abdelraheem MG. Preoperative intravenous dexamethasone combined with glossopharyngeal nerve block: role in pediatric postoperative analgesia following tonsillectomy. Eur Arch Otorhinolaryngol 2009;266:1815-9.

$24 \mathrm{Kim}$ EM, Lee JR, Koo BN, et al. Analgesic efficacy of cauda dexamethasone combined with ropivacaine in children undergoing orchiopexy. Br J Anaesth 2014;112:885-91.

25 Czarnetzki $\mathrm{C}$, Elia N, Tramèr MR. Bleeding risk and dexamethasone use in children undergoing tonsillectomy. JAMA 2013;309:437-8.

26 Tamez-Pérez HE, Quintanilla-Flores DL, Rodríguez-Gutiérrez R, et al. Steroid hyperglycemia: prevalence, early detection and therapeutic recommendations: a narrative review. World J Diabetes 2015;6:1073-81.

27 Breen TW, Shapiro T, Glass B, et al. Epidural anesthesia for labor in an ambulatory patient. Anesth Analg 1993;77:919???924-24.

28 Fournier R, Van Gessel E, Gaggero G, et al. Postoperative analgesia with "3-in-1" femoral nerve block after prosthetic hip surgery. Can J Anaesth 1998;45:34-8. 